\title{
THE PRIEST-LANGE REFLECTOMETER APPLIED TO NEARLY WHITE PORCELAIN ENAMELS
}

\author{
By Irwin G. Priest ${ }^{1}$
}

\begin{abstract}
The Priest-Lange reflectometer is described in detail and the theory of its use given for determining relative apparent reflectance for various spectral distributions of illumination. A method for measuring spectra' selectivity of reflectance is also described together with a method for measuring diffuse-plus-specular reflectance as distinguished from diffuse reflectance alone for perfectly polished specimens. The application of the instrument to porcelain enamel samples is illustrated by a detailed account of measurements made on seven typical samples. The method for measuring diffuse-plus-specular reflectance as distinguished from diffuse reflectance is shown to be inapplicable to enamel samples because of their optical imperfections, but measurements of spectral selectivity are shown to give results in close correlation with the colors of the samples observed directly.
\end{abstract}

CONTENTS

I. Introduction

1. Form of the surfaces

2. Uniformity of reflectance over the surface of a single specimen

3. Gloss _ _ _ _ _ _ _ _ _ _ 531

II. The reflectometer

III. Methods of measurement

1. Measurement of reflectance of any specimen relative to a standard for light of a given spectral distribution

2. Measurement of spectral selectivity of reflectance

3. Measurement of diffuse-plus-specular reflectance as distinguished

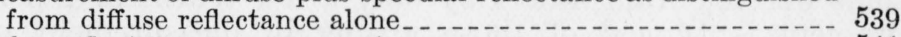

IV. Standard for reflectance measurements

V. Results of the measurement of seven porcelain enamels _._._._. 542

1. Variation of reflectance over the surface of specimen $48, \ldots 54$

2. Spectral reflectance of specimens 4,48 , and 79 relative to mag-

3. Difference between diffuse-plus-specular reflectance and diffuse reflectance alone

4. Apparent reflectance of specimen 48

5. Apparent reflectance of other specimens relative to specimen $48_{-} \quad 545$

6. Spectral selectivity of the specimens

7. The colors of the specimens.

(a) The colors of specimens 4,48 , and 79 , computed from data on spectral reflectance..... 546

(b) The colors directly observed

${ }^{1}$ Deceased. From a partially completed report of a cooperative investigation with the McGean Chemical Co. The report was prepared by Mr. Priest in 1929-30; it has been adapted for publication by Deane B. Judd in 1935. The reflectometer has been used more and more widely in the enamel industry since 1930 and is known as the Priest-Lange reflectometer (see, for example, Measurement of Opacity and Color, Am. Enameler 6, 3 (1933)), but no adequate description of it has yet been published. 


\section{INTRODUCTION}

This paper deals with the measurement of the light-reflecting characteristics of glossy, near-white, porcelain enamels by means of the Priest-Lange reflectometer. The measurements reported refer to seven specimens of porcelain enamel, on sheet steel, identified respectively by the numbers $4,29,48,63,79,92$, and 114 . They are considered typical in uniformity and in character of surface. Certain characteristics of the specimens which were far from ideal for the purpose of making highly precise measurements of reflectance will be discussed in turn.

\section{FORM OF THE SURFACES}

Roughly speaking, the specimens may be called flat, their irregular departures from flatness being of the order of $0.1 \mathrm{~mm}$. However, all were irregularly wavy and so far from plane that (although they give notable specular reflection) the virtual images of objects, using the specimens as mirrors, were either quite unrecognizable or vaguely recognizable only as very indefinite blotches. The departure of the surfaces from planeness caused some inconvenience in making the measurements and necessitated more work than would be required for plane specimens, in order to assure confidence in the results. However, it is not believed that the final results need be essentially less reliable than would those on optically plane specimens.

\section{UNIFORMITY OF REFLECTANCE OVER THE SURFACE OF A SINGLE SPECIMEN}

The chief object of the measurements was that of finding the reflectance of each of the specimens relative to one of them (48) taken as a standard. Such data can be given without qualification only if the reflectance is uniform over the whole area of each specimen. The total variation of reflectance among the seven different specimens was found to be less than 10 percent of the mean reflectance, while some differed from others by only a few tenths of 1 percent. This problem is typical of those arising in measurement of porcelain enamels. If the variation of reflectance over the area of a given specimen is of the same order of magnitude as that between different samples, it is evident that their grading on the basis of reflectance will have little significance, and may even be misleading. It is also to be remembered that small variations in brightness over a given surface may not be directly perceptible when the change from one part to another is continuous; but will only be detected by bringing the two remote parts into immediate juxtaposition optically. For specimens such as those used in this work, the reflectance at one end might well differ from that at the other by more than 2 percent and yet, if when viewed as a whole the transition from one end to the other were gradual, the surface would still appear to be uniformly bright. The magnitude of this source of error has been estimated by making a detailed analysis of reflectances at different parts of the surface of specimen 48 . 


\section{GLOSS}

It should be noted that measuring and specifying the reflectance of glossy surfaces such as these is much less simple than for perfectly diffusing (matt) samples. If an optically smooth enamel is receiving light from an extended source (for example, the sky or the wall of the illumination chamber in the reflectometer described below), and is held at such an angle with the observer's line of sight that his eye receives from it, as from a mirror, regularly reflected light, it will appear brighter than if it is set so that such regularly reflected light does not enter his eye. In the latter case, the brightness is due solely to the light reflected diffusely by the body of the enamel; that is, from light which has penetrated into the body, suffered multiple reflections from the particles within it, and then emerged from it. In the former case, the brightness is due to such diffusely reflected light plus the light specularly reflected from the glossy surface. In effect, the observer is viewing two things simultaneously in the same line of sight: (1) The body of the enamel made visible by the light which it diffuses in all directions, and (2) the virtual image of the sky or illuminating surface as seen in a mirror. The total brightness is the sum of the brightnesses associated respectively with these two things. We shall speak of diffuse brightness and the diffuse reflectance when we refer to the brightness or reflectance due solely to diffuse reflection; and of specular reflectance when we refer to the reflectance due solely to the mirror-action of the surface. As will be seen, we have attempted to measure the diffuse reflectance of the enamels separately, and have measured (for some specimens) the diffuse and specular components together. We could not, of course, measure the specular reflectance alone, but we have attempted to compute it from the other measurements.

\section{THE REFLECTOMETER}

The reflectometer consists essentially of (1) a Martens photometer and (2) an "illumination sphere." The Martens photometer ${ }^{2}$ has the following features essential to the present discussion. On looking into the instrument (eye at point $\mathrm{E}$ in fig. 1) the observer sees a circular photometric field divided on a diameter. One-half of this field is illuminated by light coming solely from one surface while the other half is illuminated by light coming solely from another surface. By turning the analyzer of the photometer the observer makes the two halves equal in brightness and then computes from such setting ("circular scale in degrees", fig. 1) the ratio of brightness of the two surfaces under comparison.

The illumination sphere is a hollow sphere, the inside surface of which is coated with magnesium oxide. There are open holes in the sphere at top and bottom. Inside, it is illuminated by four ${ }^{3}$ small lamps equally spaced around the equatorial belt. These lamps are ordinary 27 candlepower concentrated-filament automobile headlight lamps, commercially rated at 2.1 amperes. On each bulb has been placed a small opaque disk (marked "shadow disks" in fig. 1) which shades the bottom hole of the sphere from the re-

2 F. F. Martens, Über ein neues Polarisationsphotometer, Phys. Z. 1, 299-303 (1900).

3 Greater brightness is obtained in some late rmodels by using ten lamps instead of four. 


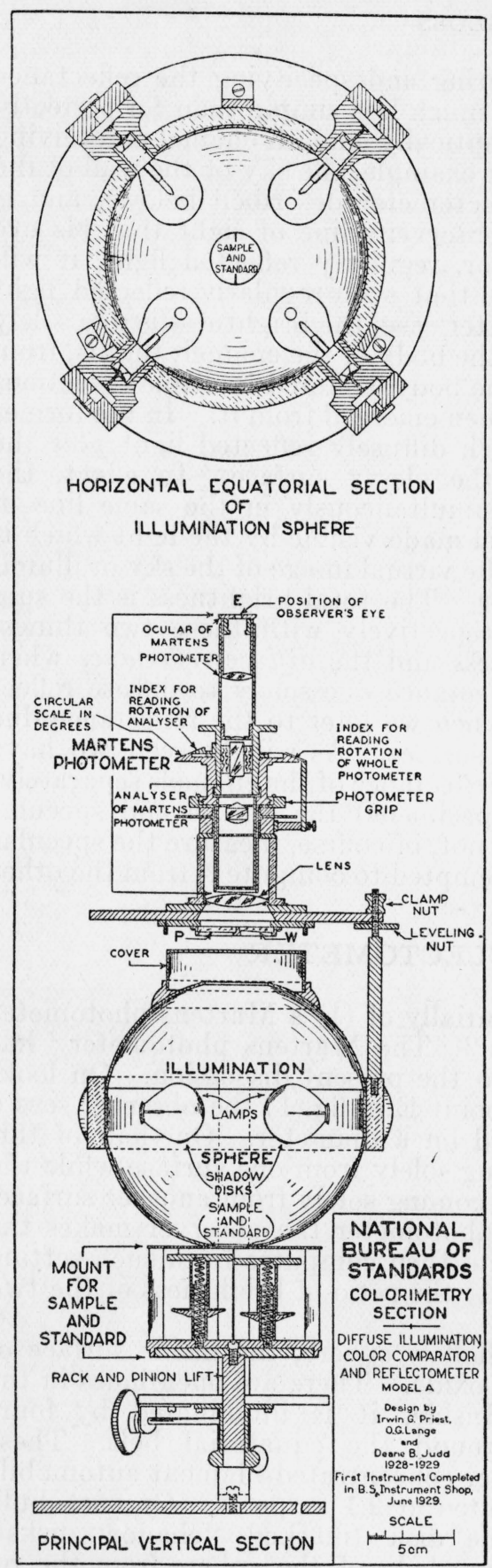

Figure 1.-The Priest-Lange reflectometer.

The essential details are shown, but for clarity some of the supporting structure is omitted. spective lamp filament, this area thus being illuminated only by light reflected from the sphere wall.

The Martens photometer is mounted above the sphere with its axis coincident with the vertical axis of the sphere; and the observer with his eye at $\mathrm{E}$ looks into the top of the photometer down along this axis.

In the method of interchange ${ }^{4}$ the "sample" and "standard" which are to be compared are placed side by side so as to cover respectively the two halves of the hole in the bottom of the sphere as shown in figure 1 , and, with plate $\mathrm{P}$ and wedge $\mathrm{W}$ removed, are imaged respectively in the two halves of the photometer field. By rotation of the stage on which they are mounted the positions of the sample and standard may be reversed. The brightness of the sample relative to the brightness of the standard under the same illumination can thus be measured.

Another method of using the instrument, and indeed the one used exclusively to obtain the present data, is the substitution method. The apparatus is arranged so that a part of the sphere wall at one side of the bottom hole (instead of a part of the area of this hole as in the foregoing paragraph) is imaged in one-half of the photometer field. This is accomplished by means of the glass wedge W. The plane parallel plate $\mathrm{P}$ of the same glass compensates for the loss of light caused by the wedge. Both pieces are made of borosilicate crown glass; and the thickness of the plate is equal to the average thickness of the wedge. The positions of the plate and wedge may be reversed, the

4 H. J. MeNicholas, Equipment for Routine Spectral Transmission and Reflection Measurements, BS J. Research 1, 819-829 (1928) RP30. See particularly eq 6 and 35 . 


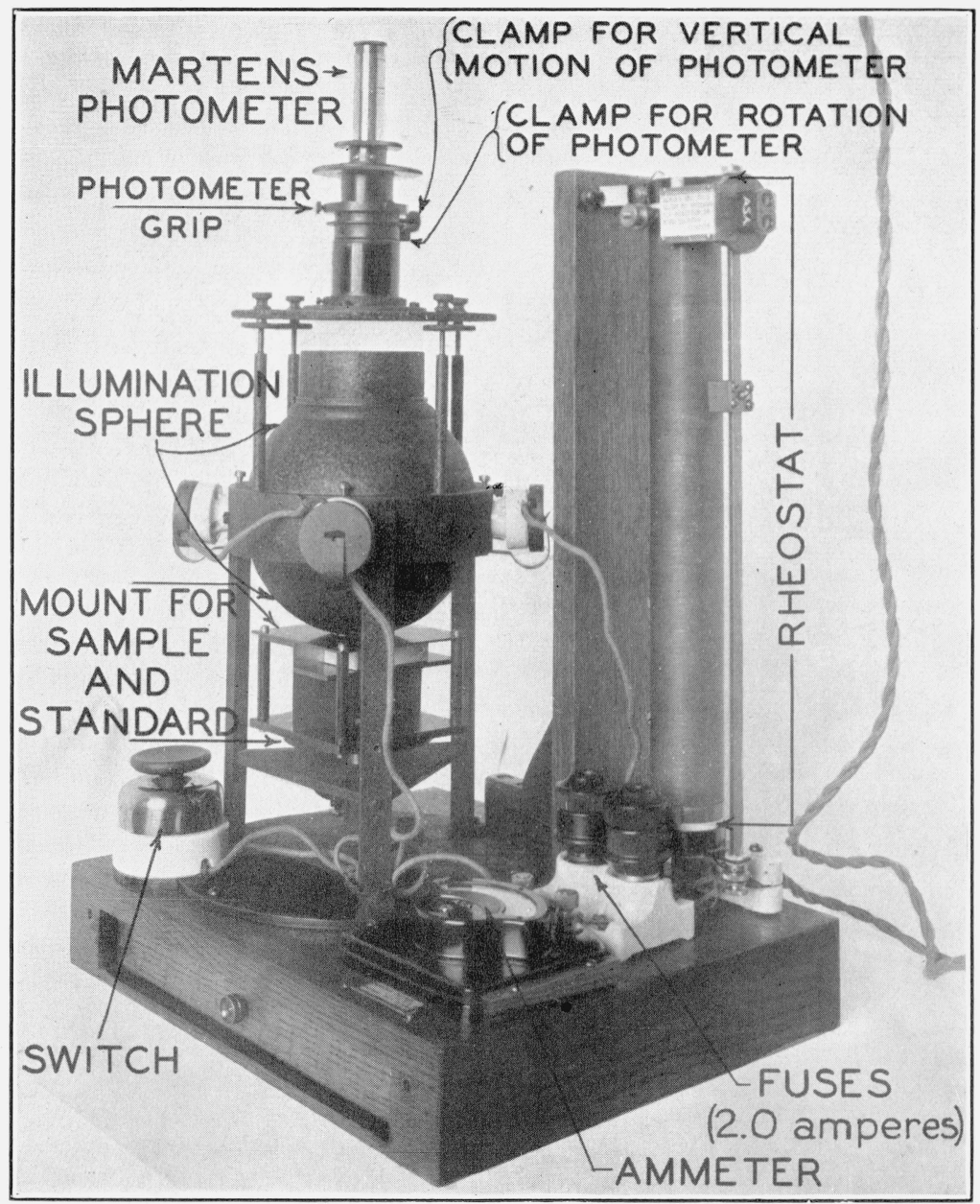

Figure 2.-The Priest-Lange reflectometer and accessory parts.

The wedge $\mathrm{W}$ and plate $\mathrm{P}$ shown in figure 1 had not yet been installed when this photograph was taken. 
thin edge of the wedge always being toward the plate. Light from the sphere wall passes through wedge $W$ and illuminates one-half of the photometer field. Light from the specimen at the hole in the bottom of the sphere passes through plate $\mathrm{P}$ and illuminates the other half of the field. ${ }^{5}$ A sample may now be compared with a standard by the substitution method. Let the standard be placed so as to cover the hole in the bottom of the sphere, and let the photometer field be matched. Let the sample now be substituted for the standard and let the field be matched again. The ratio of the brightness of the sample to the brightness of the standard under the same illumination may be computed from the photometer-scale readings in the two cases, as is explained below.

The spectral distribution of the light used in the measurements is fixed by the nature of the lamp filaments and the current in them, the selective reflectance of the sphere wall, and the ray filter which is inserted between the observer's eye and the photometer ocular. The four filters used are as follows: (1) the "daylight" filter, which is chosen so that the reflectance measurements with it are for artificial sunlight; ${ }^{6}(2)$ a blue filter transmitting light of a narrow range of wave length with spectral centroid at about $460 \mathrm{~m} \mu$; (3) a similar green filter with spectral centroid at about $540 \mathrm{~m} \mu$; and (4) a similar red filter with spectral centroid at about $650 \mathrm{~m} \mu$.

The lens placed above the plate and wedge has a twofold purpose; it directs the line of sight towards the desired areas and it controls the condition of focus of the areas viewed. As shown in figure 1, with the end of the photometer close to the lens, the areas viewed are semicircles of $25-\mathrm{mm}$ diameter; and any details of the sample are visible in the photometric field. But, if the photometer be withdrawn from the lens by about $5 \mathrm{~cm}$ (see, in fig. 2 , clamp for vertical motion of photometer) the area viewed is only of $12-\mathrm{mm}$ diameter and is out of focus so that irregularities in the sample cause little hindrance in making the settings for photometric match.

Figure 2 is a photograph of the reflectometer together with the accessory electrical parts (rheostat, ammeter, and switch), all of which are in series with the four lamps which are themselves in series. The instrument is operated on a regular 110-volt lighting circuit, the desired current (about 1.7 to 1.9 amperes) being set by means of the rheostat. No precise regulation of current is required.

\section{METHODS OF MEASUREMENT}

\section{MEASUREMENT OF REFLECTANCE OF ANY SPECIMEN RELA-} TIVE TO A STANDARD FOR LIGHT OF A GIVEN SPECTRAL DISTRIBUTION

This measurement is accomplished by the substitution method just described. Let $a_{\mathrm{x}}$ be the photometer scale reading (in circular degrees) required for matching the two halves of the photometer field when the sample is in place, and let $a_{\mathrm{s}}$ be a similar reading referring to the standard (which may be, for example, magnesium oxide or another

\footnotetext{
5 It was found desirable in 1933 to remove plate $\mathrm{P}$ because light scattered by dust collecting on its surfaces caused appreciable errors in measuring apparent reflectance relative to magnesium oxide for dark samples. This does not interfere with any use of the instrument described herein.

${ }^{6}$ Sunlight is somewhat yellower than average daylight, but the difference is too small to have any significant effect on measurements of such samples as these.
} 
of the specimens, say specimen 48). W From"the theory of the Martens photometer:

$$
B_{\mathrm{x}} / B_{\mathrm{s}}=\left(\tan ^{2} a_{\mathrm{x}}\right) /\left(\tan ^{2} a_{\mathrm{s}}\right)
$$

where $B_{\mathrm{x}}$ and $B_{\mathrm{s}}$ are, respectively, the brightness of the specimen and standard when they are under the same illumination. This ratio is the apparent reflectance of the specimen relative to the standard for the prescribed type of illumination and angle of view. By making

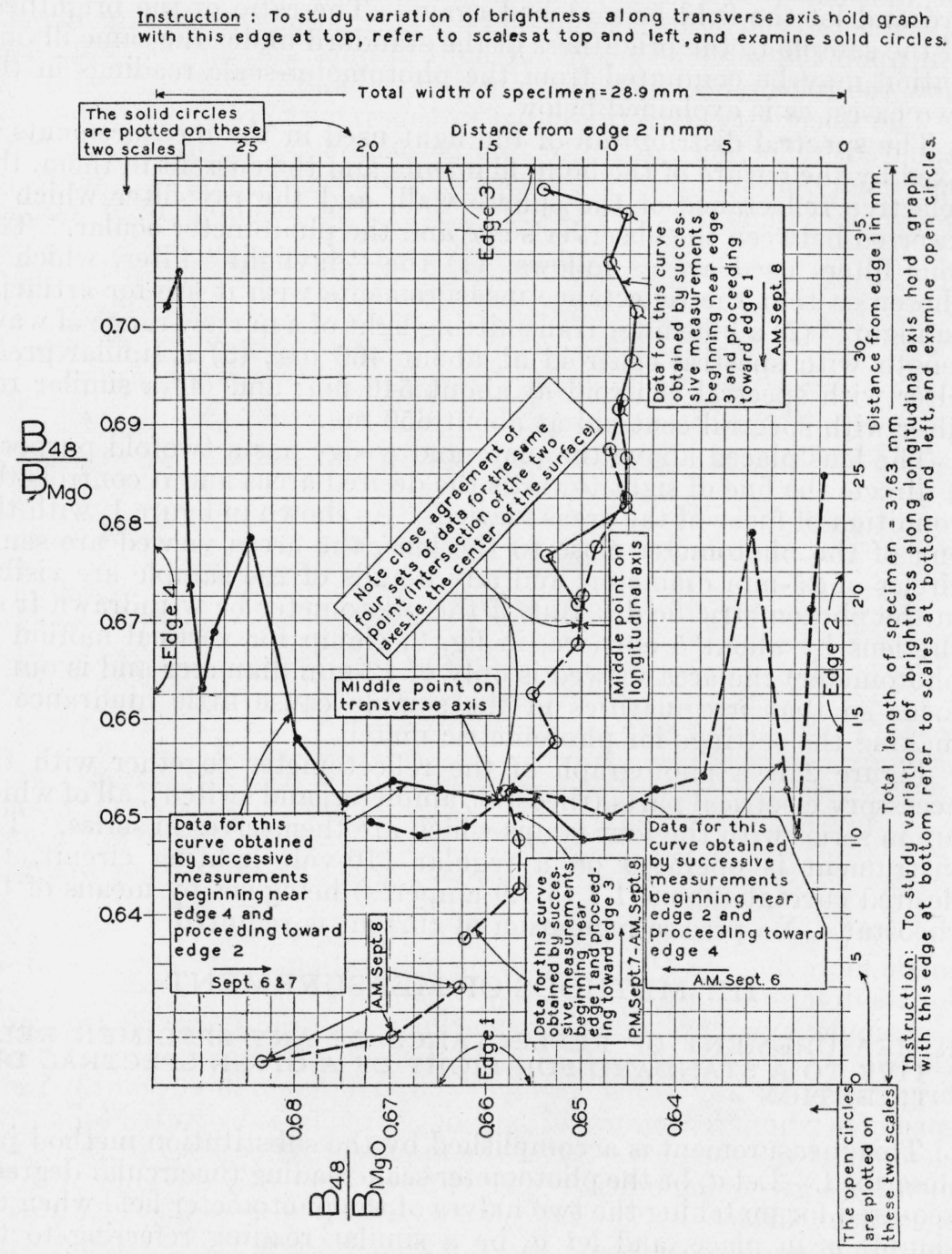

FIGURE 3.-Variation of reflectance over the surface of specimen 48.

the observation with different ray filters over the ocular of the photometer, such brightness ratios may be determined for different spectral distributions of light. It was in this manner that the data shown in figures 3 and 5 and by crosses in figure 4 were obtained; these data are discussed in section $V$. 


\section{MEASUREMENT OF SPECTRAL SELECTIVITY OF REFLECTANCE}

The theory of the determination of spectral selectivity of reflectance is similar to the above but somewhat less simple. The definition of reflectance is:

\section{Luminous flux proceeding from the specimen}

\section{Luminous flux incident on the specimen}

or, in other words, the ratio of the quantity of light reflected from the specimen to the light incident on it. This ratio is, in general, dependent upon the wave length of the light in question; and the data show how the reflectance varies with the wave length.

The selectivity data presented in this report are given in terms of apparent reflectance in a direction perpendicular to the surface of the specimen for completely diffused illumination. We designate this particular apparent reflectance as $R$. The meaning of $R$ may be

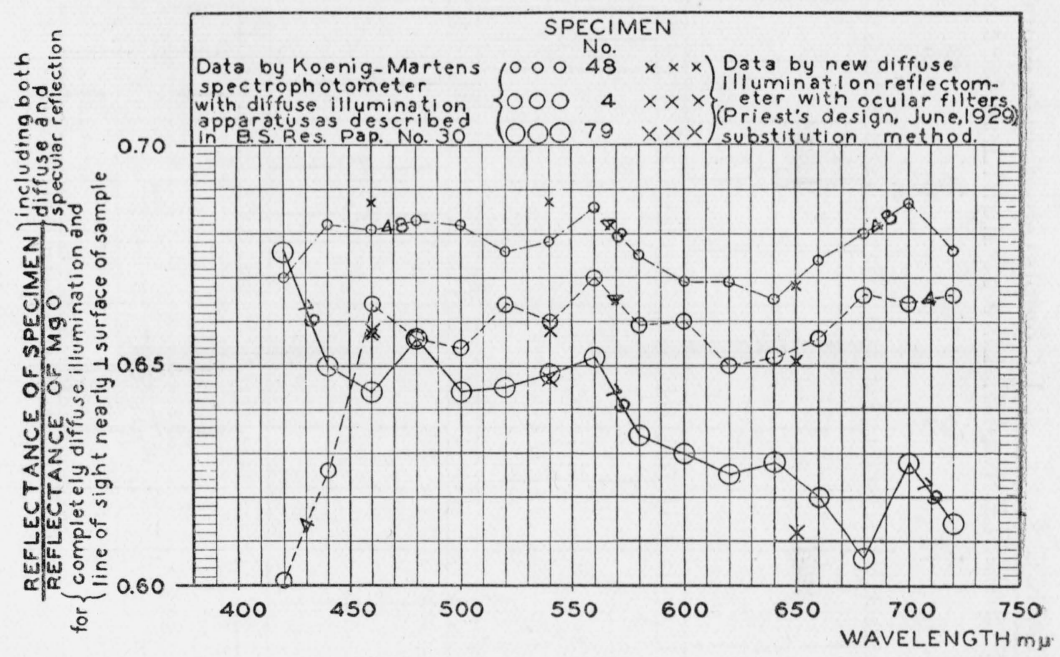

Figure 4.-Spectral reflectance of specimens 4, 48, and 79 relative to magnesium oxide.

made more definite by the following illustration of the ideal conditions for its determination.

Assume a hollow sphere such that the brightness of any small element of the inside surface viewed from any point is equal to the brightness of any other element viewed from any point. Let a specimen whose reflectance is to be measured be substituted for a small element of this surface. Then the apparent reflectance of this specimen for a given angle between the line of sight and the normal to the specimen surface is the reflectance which a completely diffusing specimen would need have in order that its brightness should equal the brightness of the given specimen when illuminated and viewed. under the same conditions. 
Under the ideal condition of completely diffused illumination we would have

$$
R=B^{\prime}{ }_{\mathrm{x}} / B^{\prime}{ }_{\mathrm{c}}
$$

where $B^{\prime}{ }_{x}$ is the brightness of the specimen viewed in a direction normal to its surface, and $B^{\prime}{ }_{\mathrm{c}}$ is the brightness of the sphere wall.

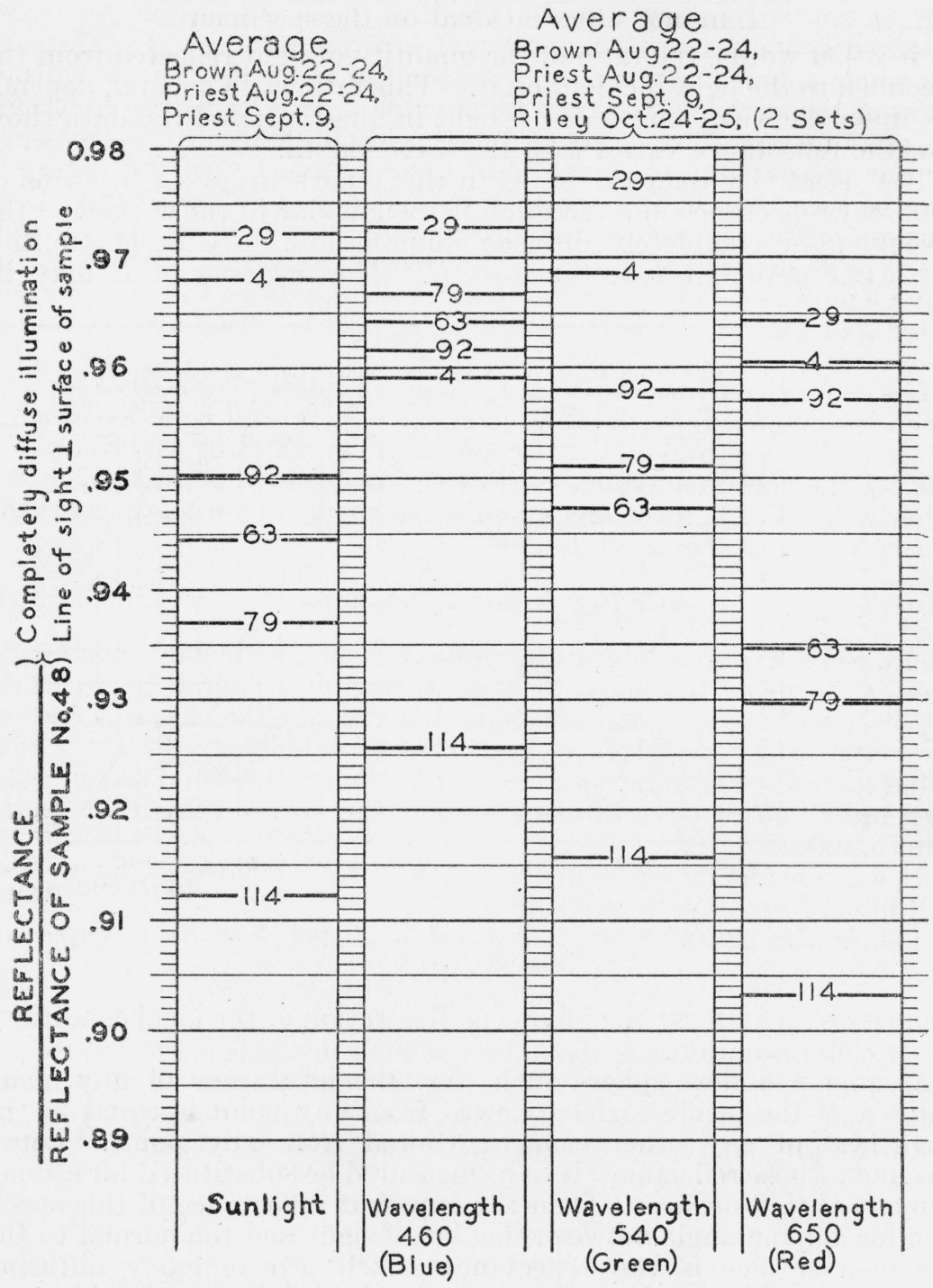

FIGURE 5.-Reflectance of other specimens relative to specimen 48.

Of course, the actual apparatus (fig. 1) used to obtain the results reported here does not fully realize the ideal condition of completely diffused illumination. Very little light comes to the sample from the viewing hole; and the sphere wall, itself, viewed from the sample is 
not equally bright over its entire surface; furthermore, the lights with their shadow disks introduce slight irregularities.

Therefore, instead of the simple equation, $R=B^{\prime}{ }_{\mathrm{x}} / B^{\prime}{ }_{\mathrm{c}}$, we have in practice with this reflectometer the analogous equation:

$$
R=K_{\mathrm{x}}\left(B_{\mathrm{x}} / B_{\mathrm{c}}\right) \text {, }
$$

where $K_{\mathrm{x}}$ is chiefly a constant of the apparatus measuring, for light of a given spectral-energy distribution, how much the brightness of the observed spot fails to be representative of the average brightness of the whole sphere. $K_{\mathrm{x}}$ also depends somewhat on the diffusing properties of the sample. It would be possible to determine the constant, $K_{\mathrm{x}}$, as a function of wave length, but this has been deemed unnecessary for our present purpose since from the construction of the sphere it may be seen that $K_{\mathrm{x}}$ is essentially independent of wave length. The purpose of the selectivity measurements is merely to report ratios of the type $R_{1} / R_{2}$, where $R_{1}$ and $R_{2}$ are respectively the values of $R$ for wave lengths $\lambda_{1}$ and $\lambda_{2}$ (or for spectral distributions of energy designated as 1 and 2). It is obvious that $K_{\mathrm{x}}$ will be eliminated in taking such a ratio.

Let us now consider the determination of ratios of this type for any given specimen. Let a small area of the sphere wall near the bottom be imaged in the half of the photometer field which is dark for $a=0$; and let the specimen which closes the bottom hole be imaged in the other half. For light of any given wave length $\lambda_{1}$ we have, from the theory of the Martens photometer,

$$
\left(B_{\mathrm{x}} / B_{\mathrm{c}}\right)_{1}=\left(\tan ^{2} a_{1}\right) /\left(\tan ^{2}\left(a_{0}\right)_{1}\right)
$$

where the subscripts 1 indicate values for the particular wave length used, $\lambda_{1}, a_{1}$ being the photometer-scale reading required to make the two halves of the photometer field match and $\left(a_{0}\right)_{1}$ the like scale reading for match when two surfaces known to be equally bright are substituted for the sphere and specimen, while the observer and the photometer and all of its attached parts except the sphere remain as in the determination of $a_{1}$.

If we consider measurements for two wave lengths, $\lambda_{1}$ and $\lambda_{2}$ we will have, from equations 2 and 3

$$
\frac{R_{1}}{R_{2}}=\frac{\left(\tan ^{2} a_{1}\right) /\left(\tan ^{2}\left(a_{0}\right)_{1}\right)}{\left(\tan ^{2} a_{2}\right) /\left(\tan ^{2}\left(a_{0}\right)_{2}\right)}
$$

or, if it is arranged that the sphere wall is imaged in the half of the photometer field which is dark for $a=90^{\circ}$ and the specimen is in the other half, we have cotangents instead of the tangents in eq 4 .

In the present report we deal with values of $R$ defined as follows:

$$
\begin{aligned}
& R_{\mathrm{b}} \text { is } R \text { for wave length } 460 \mathrm{~m} \mu . \\
& R_{\mathrm{g}} \text { is } R \text { for wave length } 540 \mathrm{~m} \mu . \\
& R_{\mathrm{r}} \text { is } R \text { for wave length } 650 \mathrm{~m} \mu . \\
& R_{\mathrm{m}} \text { is the mean of } R_{\mathrm{b}}, R_{\mathrm{g}} \text {, and } R_{\mathrm{r}} \text {. } \\
& R_{\mathrm{s}} \text { is } R \text { for sunlight. }
\end{aligned}
$$

We report values of the following ratios for each of the seven specimens: $R_{\mathrm{b}} / R_{\mathrm{m}}, R_{\mathrm{g}} / R_{\mathrm{m}}, R_{\mathrm{r}} / R_{\mathrm{m}} ; R_{\mathrm{b}} / R_{\mathrm{s}}, R_{\mathrm{g}} / R_{\mathrm{s}}, R_{\mathrm{r}} / R_{\mathrm{s}}$ (illustrated in figs. 6,7 , and 8 and discussed in section $V$ ). 
The first three ratios may be computed according to relations of the form:

$$
\frac{R_{\mathrm{b}}}{R_{\mathrm{m}}}=\frac{3\left(\tan ^{2} a_{\mathrm{b}}\right) /\left(\tan ^{2}\left(a_{0}\right)_{\mathrm{b}}\right)}{\frac{\tan ^{2} a_{\mathrm{b}}}{\tan ^{2}\left(a_{0}\right)_{\mathrm{b}}}+\frac{\tan ^{2} a_{\mathrm{g}}}{\tan ^{2}\left(a_{0}\right)_{\mathrm{g}}}+\frac{\tan ^{2} a_{\mathrm{r}}}{\tan ^{2}\left(a_{0}\right)_{\mathrm{r}}}}
$$

or from similar equations involving cotangents instead of tangents, depending on which side of the photometer field refers to the sphere wall and which to the specimen. The second three ratios may be computed according to relations of the form:

$$
\frac{R_{\mathrm{b}}}{R_{\mathrm{s}}}=\frac{\left(\tan ^{2} a_{\mathrm{b}}\right) /\left(\tan ^{2}\left(a_{0}\right)_{\mathrm{b}}\right)}{\left(\tan ^{2} a_{\mathrm{s}}\right) /\left(\tan ^{2}\left(a_{0}\right)_{\mathrm{s}}\right)}
$$

or the analogous cotangent form dependent on the conditions just mentioned.

The constants $\left(a_{0}\right)_{\mathbf{b}},\left(a_{0}\right)_{\mathbf{g}},\left(a_{0}\right)_{\mathbf{r}}$ were determined by a separate experiment as follows:

The Martens photometer and the stage upon which it is mounted, together with the lens and the wedge and plate (W and P, fig. 1 ), were removed as a unit from the position shown in figure 1 and mounted over another illumination sphere similar to that shown in figure 1, but arranged so that both halves of the photometer field were illuminated by light from the sphere wall, one half receiving light from a spot to the left of the bottom pole of the sphere while the other half received light from a spot to the right of this pole. With the appropriate filter (blue, green, or red) to determine $\left(a_{0}\right)_{\mathbf{b}},\left(a_{0}\right)_{\mathbf{g}}$, or $\left(a_{0}\right)_{\mathrm{r}}$ over the ocular, and with the photometer field oriented with respect to the observer's right and left just as in the setting of angle $a$ for the reflectance measurements, the two halves of the field were matched by turning the photometer analyzer, and the photometer scale reading noted. The whole illumination sphere was then rotated and displaced under the photometer (all things else remaining undisturbed) so as to image in the right half of the photometer field the part of the sphere wall formerly imaged in the left half and vice versa. The two halves of the photometer field were again matched by turning the photometer analyzer, and the photometer scale reading was noted. The mean of the two scale readings just mentioned was taken as equal to $\left(a_{0}\right)_{\mathrm{b}}$, $\left(a_{0}\right)_{\mathrm{g}}$, or $\left(a_{0}\right)_{\mathrm{r}}$, depending upon the ocular filter used in making the photometric matches. Each value in table 1 is a mean resulting from 100 separate settings of the angle $a$.

$\mathrm{T}_{\mathrm{ABLE}}$ 1.-Cotangents squared of $\left(a_{0}\right)_{\mathbf{b}},\left(a_{0}\right)_{\mathbf{B}}$, and $\left(a_{0}\right)_{\mathbf{r}}$ for two observers

\begin{tabular}{|c|c|c|c|}
\hline $\begin{array}{l}\text { Priest_. } \\
\text { Riley }\end{array}$ & $\begin{array}{r}\cot ^{2}\left(a_{0}\right)_{\mathrm{b}} \\
1.008 \\
1.017\end{array}$ & $\begin{array}{r}\cot ^{2}\left(a_{0}\right)_{\mathrm{g}} \\
1.002 \\
1.013\end{array}$ & $\begin{array}{r}\cot ^{2}\left(a_{0}\right)_{r} \\
1.008 \\
1.014\end{array}$ \\
\hline
\end{tabular}

For Wedge in Field Dark for $a=0^{\circ}$

\begin{tabular}{|c|c|c|c|}
\hline 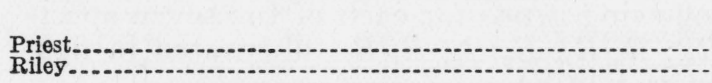 & $\begin{array}{r}\cot ^{2}\left(a_{0}\right) \mathrm{b} \\
1.019 \\
1.026\end{array}$ & $\begin{array}{r}\cot ^{2}\left(a_{0}\right)_{\mathrm{K}} \\
1.013 \\
1.027\end{array}$ & $\begin{array}{r}\cot ^{2}\left(a_{0}\right) \\
1.026 \\
1.026\end{array}$ \\
\hline
\end{tabular}

For Wedge in Field Dark for $a=90^{\circ}$ 
It appears from table 1 that in reducing observations of spectral selectivity (particularly for observer Riley) we could introduce the simplifying equation:

$$
\left(a_{0}\right)_{\mathrm{b}}=\left(a_{0}\right)_{\mathrm{g}}=\left(a_{0}\right)_{\mathrm{r}}
$$

without introducing any error greater than that necessarily inherent in the result from other causes (that is, a few tenths of 1 percent). If this simplifying equation be introduced into eq 5 , the much simpler form for computation, eq 7 , results:

$$
\frac{R_{\mathrm{b}}}{R_{\mathrm{m}}}=\frac{3 \tan { }^{2} a_{\mathrm{b}}}{\tan ^{2} a_{\mathrm{b}}+\tan ^{2} a_{\mathrm{g}}+\tan ^{2} a_{\mathrm{r}}} .
$$

This may be used for all cases except those in which we hope to reduce the uncertainty in the final result to less than 1 percent of the reflectance.

In general, determination of $\left(a_{0}\right)_{\mathrm{b}},\left(a_{0}\right)_{\mathrm{g}}$, and $\left(a_{0}\right)_{\mathrm{r}}$ need not involve a separate illumination sphere. All that is required is a surface of nearly uniform brightness so arranged that the two observed spots can be interchanged without disturbing the rest of the system.

\section{MEASUREMENT OF DIFFUSE-PLUS-SPECULAR REFLECTANCE AS DISTINGUISHED FROM DIFFUSE REFLECTANCE ALONE}

If a plane mirror (for example, a plane polished sheet of silver or a plane polished plate of black glass) be placed in the position of the sample or standard (on the stage just below the hole in the bottom of the sphere) with its surface perpendicular to the axis of the photometer, the half of the photometer field in which the hole is imaged will be dark because the virtual image of the dark hole in the top of the sphere will then alone appear in this field. If a diffusing surface (instead of a mirror) be placed in this position, the same half of the field will be illuminated by the light diffusely reflected from this surface in the direction perpendicular to it. If the diffusing surface be tilted so that the perpendicular to it makes an angle of about 3 to $4^{\circ}$ with the axis of the photometer, its brightness will not be sensibly changed, provided that its distance from the bottom of the sphere is not increased to more than $1 \mathrm{~mm}$. (By actual test, increasing the distance of the surface from the sphere bottom from 0 to $1.0 \mathrm{~mm}$ decreases the brightness by 0.35 percent; increasing the distance from 0 to $1.5 \mathrm{~mm}$ decreases the brightness 0.8 percent. ${ }^{7}$ ) If, on the other hand, a mirror be placed in the sample position with the perpendicular to its surface making an angle of 3 or $4^{\circ}$ with the photometer axis, one will see in the photometer field a virtual image of a part of the sphere wall near the top of the sphere. The brightness of the virtual image will be equal to the brightness of the sphere wall multiplied by the reflectance of the mirror for normal incidence. (The reflectance of a mirror for normal incidence is sensibly equal to its reflectance for angle of incidence equal to $4^{\circ}$.) If now, instead of either a perfect diffusor or a perfect mirror, we have to deal with a specimen which reflects diffusely from the body of its material but is coated with

\footnotetext{
7 The decrease in brightness to be expected has been computed from the geometry of the apparatus and found to depend importantly on the size of the sample hole, thus:

Distance, sample to sphere bottom, mm

Decrease for 3-em sample hole as in apparatus used by Priest,

Decrease for 2-cm sample hole as in some more recent models._._._percent_._ 0.24 $0.98 \quad 2.20 \quad 3.86$

These computed results are in good agreement with Priest's experimental findings, but at the same time they indicate that the brightness of the sample will be noticeably decreased in some of the recently built reflectometers by a withdrawal of as much as $1.0 \mathrm{~mm}$ (D.B.J., July 1935.)
} 
a vitreous glaze which reflects as a mirror we have the following situation:

First, the specimen being placed with its surface perpendicular to the axis of the photometer, the brightness of the photometer field will be due solely to light reflected diffusely by the specimen, for no specularly reflected light will enter the photometer.

Second, the specimen being placed so that the perpendicular to its surface makes an angle of about 3 or $4^{\circ}$ with the axis of the photometer, the brightness of the photometer field will be due to light reflected diffusely plus light reflected specularly; and, since the brightness due to the diffuse component is not affected by this small angular change in position of the surface, the brightness in this case will be greater than with the surface strictly perpendicular to the photometer axis.

For certain specimens, we have determined for both of the abovementioned positions, the brightness ratio, $B_{\mathrm{x}} / B_{\mathrm{mgo}}$, where $B_{\mathrm{x}}$ is the brightness of the specimen, and $B_{\text {ago }}$ is the brightness of magnesium oxide (see eq 1). To interpret and consider the results with the least possible confusion, let us adopt symbols as follows:

$B_{\mathrm{c}}$ is the brightness of the unshaded magnesium-oxide coated sphere wall near either the top or the bottom of the sphere. (For simplicity, and without introducing any appreciable error, we assume that the brightness near the bottom is equal to the brightness near the top.)

$\left(B_{\mathrm{x}}\right)_{\mathrm{d}}$ is the brightness of the specimen due to diffuse reflection in the direction perpendicular to its surface. This is the brightness of the specimen in the direction of the vertical axis of the sphere when its surface is perpendicular to this axis.

$\left(B_{\mathrm{x}}\right)_{\mathrm{d}+\mathrm{s}}$ is the brightness of the specimen due to both diffuse and specular reflection. This is the brightness of the specimen in the direction of the vertical axis of the sphere when it is tilted so that its surface regularly reflects light from the sphere wall (near the hole in the top of the sphere) along this axis.

We then have the following apparent reflectances relative to magnesium oxide, each of which may be measured by means of the Martens photometer:

and

$$
\begin{aligned}
r_{\mathrm{d}} & =\left(B_{\mathrm{x}}\right)_{\mathrm{d}} / B_{\mathrm{Mgo}}, \\
r_{\mathrm{d}+\mathrm{s}} & =\left(B_{\mathrm{x}}\right)_{\mathrm{d}+\mathrm{s}} / B_{\mathrm{Mgo}} ;
\end{aligned}
$$

and we may also measure the brightness ratio, $B_{\mathrm{Mgo}} / B_{\mathrm{c}}$, which from eq 2 is equal to $R_{\mathrm{Mgo}} / K_{\mathrm{Mgo}}$. Let $\rho$ be the specular reflectance of the specimen surface for normal (or nearly normal) incidence. We then have obviously,

$$
\left(B_{\mathrm{x}}\right)_{\mathrm{d}+\mathrm{s}}=\left(B_{\mathrm{x}}\right)_{\mathrm{d}}+\rho B_{\mathrm{c}} .
$$

Substituting eq 10 in eq 9 , we have:

$$
r_{\mathrm{d}+\mathrm{s}}=\frac{\left(B_{\mathrm{x}}\right)_{\mathrm{d}}+\rho B_{\mathrm{c}}}{B_{\mathrm{Mgo}}} .
$$

Reducing eq 11 and substituting eq 2 and 8 , we have:

Solving for $\rho$, we have:

$$
r_{\mathrm{d}+\mathrm{s}}=r_{\mathrm{d}}+\rho\left(K_{\mathrm{MgO}} / R_{\mathrm{MgO}}\right)
$$

$$
\rho=\left(R_{\text {Mgo }} / K_{\text {Mgo }}\right)\left(r_{\mathrm{d}+\mathrm{B}}-r_{\mathrm{d}}\right) .
$$

We desire to know $r^{\prime}{ }_{\mathrm{d}+\mathrm{s}}$, the value which $r_{\mathrm{d}+\mathrm{s}}$ would assume if (instead of the actual illumination sphere which we use) the sphere were such as to make $B_{\mathrm{Mgo}} / B_{\mathrm{c}}$ equal to $R_{\mathrm{Mgo}}$, the apparent reflectance 
of magnesium oxide for completely diffused illumination and line of sight perpendicular to the surface, that is, such as to make $K=1$ for magnesium oxide. In such a sphere, we would have:

$$
r^{\prime}{ }_{\mathrm{d}+\mathrm{s}}=r_{\mathrm{d}}^{\prime}+\rho / R_{\mathrm{MgO}}
$$

where $r^{\prime}{ }_{\mathrm{d}}$ for this ideal sphere is analogous to $r_{\mathrm{d}}$ in our actual sphere. But we may assume for enamel surfaces $r^{\prime}$ equal to $r_{\mathrm{d}}$ within experimental error and then we have:

or

$$
r_{\mathrm{d}+\mathrm{s}}^{\prime}=r_{\mathrm{d}}+\rho / R_{\mathrm{MgO}}
$$

$$
r_{\mathrm{d}+\mathrm{s}}^{\prime}=r_{\mathrm{d}}+\left(r_{\mathrm{d}+\mathrm{s}}-r_{\mathrm{d}}\right) / K_{\mathrm{mgo}}
$$

It is to be recalled now that $r_{\mathrm{d}+\mathrm{s}}$ and $r_{\mathrm{d}}$ are directly measured quantities. For the present specimens, the difference, $r_{\mathrm{d}+\mathrm{s}}-r_{\mathrm{d}}$, has been found experimentally to vary only between 0.014 and 0.034 . In the actual apparatus used to measure $r_{\mathrm{d}}$ and $r_{\mathrm{d}+\mathrm{s}}$, the value of $R_{\mathrm{Mgo}} / K_{\mathrm{Mgo}}$ has been experimentally found to be about 0.94 ; the value of $R_{\text {Mgo }}$ is known to lie between 0.97 and 0.98 ; hence $1 / K_{\text {Mgo }}$ is equal to about 0.96 . Since we shall not attempt to report $r^{\prime}{ }_{\mathrm{d}+\mathrm{s}}$ to more than three decimal places, it is obvious from eq 13 that an uncertainty of 2 percent in $1 / K$ is negligible and, for present purposes, we may take $1 / K$ as 0.96 without further discussion not only for magnesium oxide but also for these enamel specimens whose diffusing properties are similar.

It is also worth noting that the accuracy with which $r^{\prime}{ }_{\mathrm{d}+\mathrm{s}}$ is determined depends almost entirely on the accuracy with which $r_{\mathrm{d}+\mathrm{s}}$ is measured. This may be seen by rewriting eq 13 in the form:

$$
r_{\mathrm{d}+\mathrm{s}}^{\prime}=r_{\mathrm{d}+\mathrm{s}}(1 / K)+r_{\mathrm{d}}(1-1 / K) \text {. }
$$

The values of $r_{\mathrm{d}}, r_{\mathrm{d}+\mathrm{s}}, \rho$, and $r_{\mathrm{d}+\mathrm{s}}^{\prime}$ for specimens 4,48 , and 79 are given in table 2 , and are discussed in section $\mathrm{V}$.

The values plotted by crosses in figure 4 have been computed by eq 13 , taking $1 / K=0.96$. As a practical matter, however, it may be noted that, with these specimens, we could take $r^{\prime}{ }_{\mathrm{d}+\mathrm{s}}$ equal to $r_{\mathrm{d}+\mathrm{s}}$ instead of computing by eq 13, without introducing any error greater than the uncertainty in the data.

\section{STANDARD FOR REFLECTANCE MEASUREMENTS}

The magnesium oxide used as a standard, to which the reflectance of the specimens is referred (in figs. 3 and 4 , and table 2), is prepared by burning metallic magnesium so that the magnesium oxide "smoke" is deposited on a surface held over the flame (about $10 \mathrm{~cm}$ from the burning metal). ${ }^{8}$ Successive layers are deposited to such a thickness that increasing the thickness produces no further change in reflectance. The critical thickness is about $0.5 \mathrm{~mm}$. The apparent reflectance ${ }^{9}$ of such a deposit for completely diffused illumination with line of sight perpendicular to the surface may be taken as between 0.97 and 0.98 . (With the present apparatus in which the angular distribution of the illumination departs from the condition of complete diffusion chiefly by reason of the viewing hole at top of

\footnotetext{
${ }^{8}$ Detailed instructions are given in Letter Circular of the National Bureau of Standards LC395, Prepa ${ }^{8}$ Detailed instructions are given in Letter Circular of the National Bureau of
ration and Colorimetric Properties of a Magnesium Oxide Reflectance Standard.

- When the sample is so thick that its reflectance depends on the material rather than its dimensions, the term "reflectivity" is often substituted for reflectance (J. Opt. Soc. Am. and Rev. Sci. Instr. 10, 178 (1925); J. Research NBS 13, 282 (1934)). The expression here might therefore be "apparent reflectivity." (D.B.J., July 1935.)
} 
the sphere, the apparent reflectance of a thick layer of magnesium oxide with line of sight perpendicular to the surface is lower than this by a few tenths of 1 percent, and may be taken as about 0.97.) We shall assume $R_{\mathrm{MgO}}=0.975$ for $\lambda=560 \mathrm{~m} \mu$ and for sunlight.

As to selectivity with respect to wave length, the reflectance for blue and green is slightly greater than for red; but the departure from the mean value over the wave-length range 460 to $650 \mathrm{~m} \mu$ is nowhere greater than 0.5 percent, as is indicated by the following data by Priest and Riley: ${ }^{10} \quad R_{\mathrm{b}} / R_{\mathrm{m}}=1.0044, R_{\mathrm{g}} / R_{\mathrm{m}}=1.0010, R_{\mathrm{r}} / R_{\mathrm{m}}=0.9946$. Assuming $R$ for wave length $560 \mathrm{~m} \mu$ as 0.975 , we estimate: $R_{\mathrm{b}}=0.979$, $R_{\mathrm{g}}=0.976, R_{\mathrm{r}}=0.970$.

\section{RESULTS OF THE MEASUREMENT OF SEVEN PORCELAIN ENAMELS}

\section{VARIATION OF REFLECTANCE OVER THE SURFACE OF SPECIMEN 48}

The specimen was mounted on a stage actuated by a micrometer screw so that it could be moved by measured steps across the field of view in a direction perpendicular to the line of sight, the plane of the specimen surface being in focus in the photometer field. By this device the images of the various points of the surface were brought to coincidence with the division line in the photometer field.

Each point plotted in figure 3 is derived from the mean of ten independent settings of brightness match for the corresponding point on the specimen. These ten brightness matches are not made in immediate succession. On the contrary, the order of observations was as follows: First, one setting of brightness match was made for the point nearest an edge, then one setting for the next nearest point, and so on, taking points in order until the point nearest the opposite edge was reached. This order of observation was then repeated nine times, giving the ten independent settings from which each of the plotted values was obtained. The ratio $B_{48} / B_{\mathrm{Mgo}}$ was computed by eq 1 . The solid circles refer to observations taken along the transverse axis; the open circles, to the longitudinal axis.

It may be concluded from figure 3 that the reflectance along the transverse axis is sensibly constant for a distance of 6 or $7 \mathrm{~mm}$ on both sides of the midpoint. Outside of these limits (that is, for strips about 6 or $8 \mathrm{~mm}$ wide adjoining the lateral edges) the measured reflectance tends to be notably higher. Near the edges, values higher than the central values by as much as 10 percent have been obtained.

Along the longitudinal axis there is also a tendency to relatively high values near the edges; but the distribution is less symmetrical than along the transverse axis, values to the side of the center toward edge 1 (also near the center) being systematically higher than values for symmetrical points on the other side of the center. However, the region extending about 4 or $5 \mathrm{~mm}$ on both sides of the center may be considered as sensibly constant (taking into account the uncertainty of the measurements).

${ }^{10}$ I. G. Priest and J. O. Riley, The Selective Reflectance of Magnesium Oxide, J. Opt. Soc. Am. 20, 156 (1930). 
In general it is difficult to interpret strictly the significance of the measurements near the edges where the enamel is usually piled up to form what is known as the "bead." The high values may be partly due to "high lights" occasioned by specular reflection from the curved surfaces of the "bead", and partly to increased thickness of enamel at the "bead." However, near the edges a photometric field unsatisfactory for precise measurements is obtained; the division line in the photometer field does not disappear when one attempts to match the two halves of the field. The chief conclusion we draw from these measurements is that precise and significant measurements to serve for intercomparing the several specimens cannot be made near their edges.

\section{SPECTRAL REFLECTANCE OF SPECIMENS 4, 48, AND 79 RELATIVE TO MAGNESIUM OXIDE}

The circles in figure 4 represent apparent spectral reflectance relative to magnesium oxide obtained on the König-Martens spectrophotometer with the illumination chamber used in routine measurements at the Bureau. ${ }^{11}$ The approximation to completely diffused illumination is so close that the measurements may be taken as for completely diffused illumination.

The crosses refer to data taken on the reflectometer here described, and, strictly speaking, are not precisely for the wave lengths at which they are plotted, but rather represent the average reflectance for a small range of wave lengths on both sides of the plotted value. The values of apparent reflectance have been corrected so as to refer to completely diffused illumination. They are the values of $r^{\prime}{ }_{\mathrm{d}+\mathrm{s}}$ given in table 2 to be discussed presently.

All values may be considered as for the center of the specimen, although the measurements by the König-Martens spectrophotometer were actually for points perhaps $7 \mathrm{~mm}$ from the center. ${ }^{12}$ The agreement between the results by the two instruments is seen to be within experimental uncertainty.

\section{DIFFERENCE BETWEEN DIFFUSE-PLUS-SPECULAR REFLECT-} ANCE AND DIFFUSE REFLECTANCE ALONE

Data illustrating the difference between diffuse-plus-specular reflectance and diffuse reflectance alone for specimens 4,48 , and 79 are shown in table 2.

From these data has been computed the average specular reflectance for normal incidence ( $\rho$ as given by eq 12), which is 0.023 . From Fresnel's reflection formula one would expect $\rho$ for a plane polished surface of glass of refractive index 1.53 to be 0.044 . As a matter of

${ }^{11}$ H. J. MeNicholas, Equipment for Routine Spectral Transmission and Reflection Measurements, BS J. Research, 1, 793 (1928) R P30. The spectral reflectance measurements on the enamels were made by Mabel E. Brown.

${ }_{12}$ Previous spectrophotometric measurements made near the edges of the samples were discarded. However, these previous data do not differ significantly from those illustrated. A consideration of all the data indicates:

(1) That most of the minor and seemingly erratic variations are probably not real. This is to be expected since the uncertainty in most of the values illustrated is probably as great as 0.01 and even more toward the ends of the spectrum. This is particularly true at $460 \mathrm{~m} \mu$ for specimen 4 , the true value of which is probably about 0.65 . However, the low values at 540 and $580 \mathrm{~m} \mu$ relative to the respective values at $560 \mathrm{~m} \mu$ were consistently obtained throughout.

(2) That the relatively strong absorptions of specimen 4 in the violet and of specimen 79 in the red are real. The coincidence between the colorimetric results computed from the illustrated data and the colors of the samples as judged by direct examination is considered later. (K.S.G., Aug. 1935.) 
fact we have measured $\rho$ for highly polished black glass of this index with this same instrument and have obtained the experimental value of $0.042_{5}$. It may also be noted that McNicholas had previously reported $\rho=0.043$ for this same piece of black glass. ${ }^{13}$ For glossy "velox" photographic paper we have also found $\rho=0.045$ with this same apparatus. It is admitted that the values of $\left(r_{\mathrm{d}+\mathrm{s}}-r_{\mathrm{d}}\right)$ given in table 2 , and consequently the values of $\rho$ may be individually uncertain by as much as 0.01 , or even 0.02 ; but it is very improbable that they are systematically lower than the true value by as much as 0.02 .

TABLE 2.-Comparison of diffuse-plus-specular reflection with diffuse reflection alone

\begin{tabular}{|c|c|c|c|c|c|c|c|c|c|c|}
\hline \multirow{2}{*}{ Quantity 1} & \multirow{2}{*}{$\begin{array}{l}\text { Specimen......... } \\
\text { Ocular filter } \\
\text { Spectral centroid.. }\end{array}$} & \multicolumn{3}{|c|}{48} & \multicolumn{3}{|c|}{4} & \multicolumn{3}{|c|}{79} \\
\hline & & $\begin{array}{c}\text { Blue } \\
460\end{array}$ & $\begin{array}{c}\text { Green } \\
540\end{array}$ & $\begin{array}{l}\text { Red } \\
650\end{array}$ & $\underset{460}{\text { Blue }}$ & $\begin{array}{c}\text { Green } \\
540\end{array}$ & $\begin{array}{c}\text { Red } \\
650\end{array}$ & $\underset{460}{\text { Blue }}$ & $\begin{array}{c}\text { Green } \\
540\end{array}$ & $\begin{array}{l}\text { Red } \\
650\end{array}$ \\
\hline $\begin{array}{l}r_{\mathrm{d}+\mathrm{s}} \\
r_{\mathrm{d}} \\
r_{\mathrm{d}+\mathrm{s}}-r_{\mathrm{d}} \\
0.96\left(r_{\mathrm{d}+\mathrm{s}}-r_{\mathrm{d}}\right) . \\
r_{\mathrm{d}+\mathrm{s}}=r_{\mathrm{d}}+\left(r_{\mathrm{d}+\mathrm{s}}\right.\end{array}$ & $/ K_{\mathrm{MgO}}$ & $\begin{array}{l}0.688 \\
.661 \\
.027 \\
.026 \\
.687\end{array}$ & $\begin{array}{l}0.689 \\
.658 \\
.031 \\
.030 \\
.688\end{array}$ & $\begin{array}{r}0.669 \\
.647 \\
.022 \\
.021 \\
.668\end{array}$ & $\begin{array}{r}0.658 \\
.633 \\
.025 \\
.024 \\
.658\end{array}$ & $\begin{array}{r}0.659 \\
.639 \\
.020 \\
.019 \\
.658\end{array}$ & $\begin{array}{l}0.653 \\
.619 \\
.034 \\
.033 \\
.652\end{array}$ & $\begin{array}{r}0.659 \\
.636 \\
.023 \\
.022 \\
.658\end{array}$ & $\begin{array}{r}0.648 \\
.626 \\
.022 \\
.021 \\
.647\end{array}$ & $\begin{array}{r}0.613 \\
.599 \\
.014 \\
.013 \\
.612\end{array}$ \\
\hline
\end{tabular}

1 See eq 13.

When one considers the known waviness of the surfaces of these specimens and the unknown degree of polish of such surfaces, the apparently low value of $\rho$ is seen to be not a matter to cause astonishment. It should be emphasized that our method of finding $\rho$ tacitly assumes that the surface is optically plane, whereas these surfaces come far from fulfilling this condition.

It may be concluded, therefore, that values of $r_{\mathrm{d}}$ do not represent diffuse reflectance solely from the body of the enamel; a small part of the diffusely reflected light comes from the surface itself.

\section{APPARENT REFLECTANCE OF SPECIMEN 48}

On the basis of all of our data we adopt the following values of $r_{\mathrm{d}}=\left(B_{48}\right)_{\mathrm{d}} / B_{\text {Mgo }}$; see eq 8 .

For sunlight $\ldots .6576$

For $\lambda_{c}=460 \mathrm{~m} \mu$

For $\lambda_{\mathrm{c}}=540 \mathrm{~m} \mu \ldots \ldots+655$

For $\lambda_{\mathrm{c}}=650 \mathrm{~m} \mu \ldots$

These relative values may be put on an absolute basis by taking into account the apparent reflectance of magnesium oxide, $R_{\mathrm{Mgo}}$, thus:

For sunlight_.......... $0.6576 \times 0.975=0.641$

For $\lambda_{\mathrm{c}}=460 \mathrm{~m} \mu \ldots \ldots+.6593 \times .979=.645$

For $\lambda_{\mathrm{c}}=540 \mathrm{~m} \mu \ldots .6575 \times .976=.642$

For $\lambda_{\mathrm{c}}=650 \mathrm{~m} \mu \ldots .6461 \times .970=.627$

${ }^{13}$ H. J. McNicholas, Absolute Methods in Reflectometry, BS J. Research 1, 53 (1928). 
The corresponding values for apparent diffuse-plus-specular reflectance are less accurate. However, approximate values (subject to an error probably less than 0.01 ) may be obtained by adding 0.023 to the corresponding values for diffuse reflectance just given.

In the case of either diffuse-plus-specular reflectance or diffuse reflectance alone, the values for any of the other specimens may be obtained by multiplying the value for specimen 48 by the appropriate relative reflectance taken from figure 5 .

\section{APPARENT REFLECTANCE OF OTHER SPECIMENS RELATIVE TO SPECIMEN 48}

The reflectance of each specimen relative to the reflectance of specimen 48 for completely diffused illumination, with line of sight

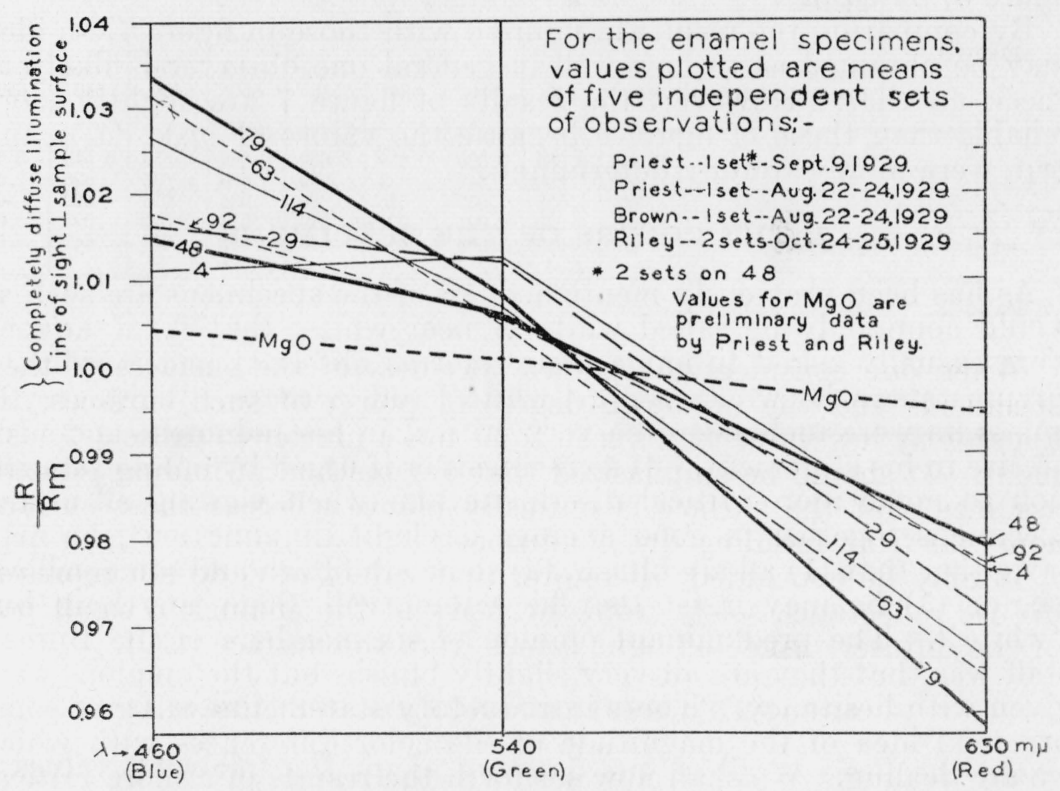

FIgURE 6.-Spectral selectivity of reflectance by equation 5, mean of all data.

The three values shown for each specimen are reflectances relative to the mean for that specimen.

perpendicular to the specimen surface, is given by figure 5 . The results shown were obtained according to eq 1 . The measurements refer to diffuse reflection but these ratios would be sensibly the same for measurements including both diffuse and specular reflection for each specimen relative to specimen 48 . Each plotted value is the result of at least 60 settings of brightness match, but no great significance should be attached to relative order of specimens, when the difference between them is less than one percent.

It may be noted: (1) that the range of sunlight reflectance in this collection of seven specimens is about 9 percent; (2) that specimen 48 is undoubtedly the lightest and specimen 114 the darkest; (3) that specimen 48 reflects some 2 or 3 percent more than its closest rival, specimen 29; and (4) that specimen 114 falls in a class by itself as notably dark relative to the others. 


\section{SPECTRAL SELECTIVITY OF THE SPECIMENS}

The selective reflectance (selective with respect to wave length) of the specimens relative to specimen 48 may be inferred from figure 5. However, as has been shown in section III above, we can measure and express the selectivity of reflectance on an absolute basis, without taking into account the reflectance of any other specimen or standard material.

The data on spectral selectivity of reflectance for these seven specimens are exhibited in figures 6,7 , and 8 . The interpretation and essential significance of these figures may be readily seen from the figures themselves and from the description of the method of measurement given in section III. The results shown in figures 6 and 7 were obtained by the method indicated by eq 5 ; those shown in figure 8 , by eq 6 .

By comparing the results in figure 6 with those in figure 7 , an idea may be obtained as to how well in general one observer is likely to check another. However, the results of figure 7 are slightly more reliable than those of figure 6 because the values of $\left(a_{0}\right)_{\mathrm{b}},\left(a_{0}\right)_{\mathrm{g}}$, and $\left(a_{0}\right)_{\mathbf{r}}$ were more carefully determined.

\section{THE COLORS OF THE SPECIMENS}

As has been previously mentioned, all of the specimens are such as would commonly be called white or near white; that is, if anyone were casually asked to name their color as observed under ordinary circumstances he would reply "white" (or, perhaps, "light gray") unless he were inclined to be very critical in his judgment and very precise in his statement. If so inclined, or if urged by cross-examination to make more critical discrimination (when viewing all of the specimens together in good average daylight illumination), he may say either that (1) all are bluish, (2) some are bluish and some yellowish, or (3) he may insist that he cannot call them anything but "white". The predominant opinion of six members of the Bureau staff was that they are all very slightly bluish; but the opinions were given with hesitancy. These introductory statements will give some practical idea of the magnitude of the color differences with which we are dealing. We shall now set forth the results of a more critical examination of the specimens.

(a) THE COLORS OF SPECIMENS 4, 48, AND 79, COMPUTED FROM DATA ON SPECTRAL REFLECTÁNCE

The basic ideas on which the computation of these color specifications from spectral reflectance depends will first be briefly set forth. The color of any one of these specimens (in sunlight) may be matched by a mixture of sunlight and homogeneous light of some wave length selected from the spectrum. The particular wave length which it is found requisite to select in order to match the color of the specimen in this manner is called the "dominant wave length" $(\Lambda)$ of that specimen. In order to match the color of the specimen it is necessary to mix the homogeneous light and the sunlight in a certain particular ratio. This ratio is specified by the purity $p$, purity being defined as the ratio of the brightness of the homogeneous component of the mixture to the brightness of the mixture itself. 


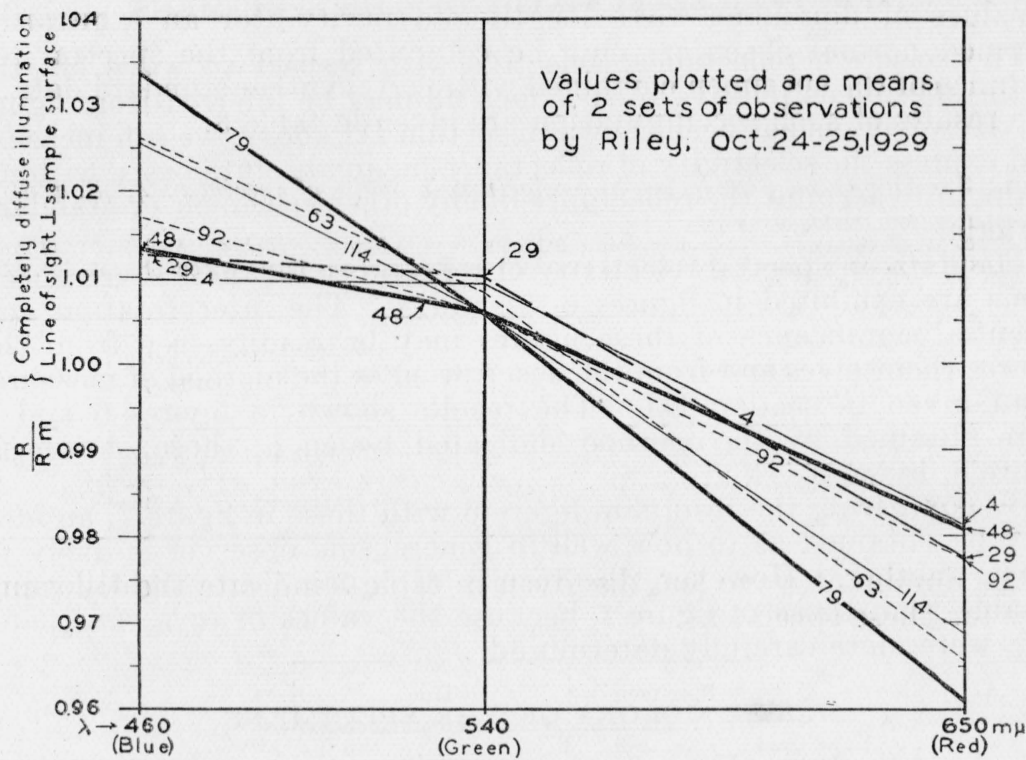

FIGURE 7.-Spectral selectivity of reflectance by equation 5, most careful determinations by one observer.

The three values shown for each specimen are reflectances relative to the mean for that specimen.

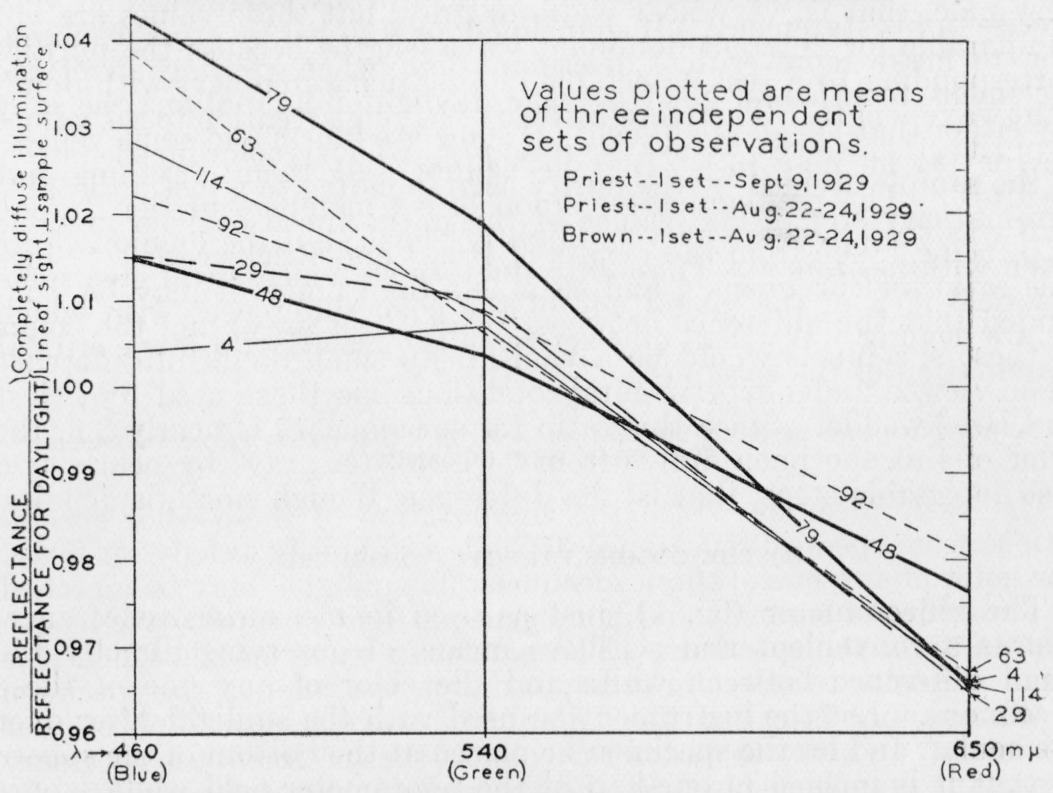

FigURE 8.-Spectral selectivity of reflectance by equation 6 .

The three values shown for each specimen are reflectances for blue, green, and red light, each relative to reflectance for sunlight. 
Values of dominant wave length and purity (for an arbitrarily assumed normal observer) may be computed from the spectral reflectance of the specimen combined with certain other standard data..$^{14}$ The results of such a computation are given in table 3.

TABLE 3.-Dominant wave length and colorimetric purity of specimens 4, 48, and 79

[Computed from the following data:

(1) Spectral reflectance relative to magnesium oxide as given in figure 4; (2) absolute selectivity of mag. nesium oxide as given in figure 6; and (3) OSA standard observer and coordinate system (J. Opt. Soc. Am. and Rev. Sci. Instr. 10, 230 (1925))].

\begin{tabular}{|c|c|c|c|}
\hline Specimen & $\begin{array}{l}\text { Dominant } \\
\text { wave length, } \\
\Lambda\end{array}$ & $\begin{array}{l}\text { Colorimetric } \\
\text { purity, } p\end{array}$ & $p / p$ \\
\hline 48 & $\begin{array}{l}565.4 \\
488.4 \\
483.4\end{array}$ & $\begin{array}{r}0.0345 \\
.0060 \\
.0105\end{array}$ & $\begin{array}{r}0.73 \\
.87 \\
1.78\end{array}$ \\
\hline
\end{tabular}

The dominant wave lengths given in table 3 indicate the following hues for these specimens:

\begin{tabular}{|c|c|}
\hline Specimen & Hue \\
\hline 48 & $\begin{array}{l}\text { Green or yellow-green. } \\
\text { Blue or blue-green. } \\
\text { Blue or blue-green. }\end{array}$ \\
\hline
\end{tabular}

The values of purity, being very small, indicate that the colors are very pale, that is, very near white or gray; but these values are not comparable for different dominant wave lengths because the purities corresponding to a just detectable chromaticity step vary with dominant wave length. Therefore, instead of paying attention to the values of purity, themselves, we use the ratio $p / p_{0}$, which is colorimetric purity of the sample divided by the purity corresponding to a just noticeable chromaticity step. The values of this ratio are also given in table $3, p_{0}$ being taken from the results of Priest and Brickwedde. ${ }^{15}$ Since this ratio for specimens 4 and 48 is less than unity, it may be concluded that the difference between "white" (or gray) and the colors of these specimens would be a vanishingly small doubtful difference when viewed under experimental conditions like those used by Priest and Brickwedde. Since this ratio for specimen 79 is nearly 2.0 , the color of this specimen differs from "white" (or gray) by nearly two just detectable steps, that is, the difference, though small, is definite.

\section{(b) THE COLORS DIRECTLY OBSERVED}

The reflectometer (fig. 1), just as used in measuring reflectance, affords a convenient and sensitive means of observing directly the small difference between white and the color of any one of these specimens. Let the instrument be used with the sunlight filter over the ocular, and let the specimen be placed at the bottom of the sphere so that it is imaged in one-half of the photometer field while a part of the sphere wall is imaged in the other half. The important point

14 These data, together with directions and forms for the computation, are given in J. Opt. Soc. Am. 23, 359 (1933)

15 I. G. Priest and F. G. Brickwedde, The Minimum Perceptible Colorimetric Purity as a Function of Dominant Wave Length with Sunlight as Neutral Standard, J. Opt. Soc. Am. and Rev. Sci. Instr. 13, 306 (1926). 
to be emphasized in this arrangement is that one-half of the field is illuminated by light which is identical in quality with the light which falls on the specimen while the other half is illuminated by light reflected from the specimen. The two halves of the field may be matched in brilliance by turning the photometer analyzer. When this has been done it is obvious that the quality difference remaining is nothing other than the difference between the color of the specimen and the color of a strictly nonselective (white or gray) surface of the same lightness when both are illuminated by sunlight.

\section{$\mathrm{T}_{\mathrm{ABLE}}$ 4.-Hues of the specimens by direct comparison of their colors under artificial sunlight illumination with the color of that illumination}

The comparison was made at equal brilliance in the Martens photometer field with the apparatus shown in figure 1.a Results for $\mathrm{MgO}$ and $\mathrm{MgCO}_{3}$ under identical conditions are shown for comparison.

\begin{tabular}{|c|c|c|c|c|c|c|c|c|c|}
\hline \multirow{2}{*}{ Observer } & \multicolumn{9}{|c|}{ Specimen } \\
\hline & 4 & 29 & 48 & 63 & 79 & 92 & 114 & $\mathrm{MgCO}_{3}$ & $\mathrm{MgO}$ \\
\hline Judd.............. & Green.- & Green... & Green.-- & Green- & Green- & Green-- & Green- & Yellow-- & Yellow? \\
\hline Gibson.............. & Green.-- & Green_- & Blue... & Blue..- & Blue... & Blue... & Blue... & Yellow?_- & Neutral. \\
\hline Brown. & Blue..- & Blue... & $\begin{array}{c}\text { Green- } \\
\text { blue. }\end{array}$ & Blue & Blue... & Blue... & Blue..- & Pink? & Blue? \\
\hline Riley........... & $\begin{array}{l}\text { B } 1 \text { u } 6- \\
\text { green. }\end{array}$ & $\begin{array}{c}\text { B } 1 \text { u e- } \\
\text { green. }\end{array}$ & $\begin{array}{l}\text { B } 1 \text { u e- } \\
\text { green. }\end{array}$ & $\begin{array}{l}\text { B } 1 \text { u e- } \\
\text { green. }\end{array}$ & $\begin{array}{l}\text { B } 1 \text { u e- } \\
\text { green. }\end{array}$ & $\begin{array}{c}\text { B } 1 \text { u e- } \\
\text { green. }\end{array}$ & $\begin{array}{c}\text { B } 1 \text { u e- } \\
\text { green. }\end{array}$ & Red.- & Neutral? \\
\hline Blue-green ratio ${ }^{3}$ & $0.67 \ldots$ & $0.67 \ldots$ & 1. $0_{z} \ldots$ & 2.0 & 2.0 & 1. 5 & 2.0 & & \\
\hline $\begin{array}{c}\text { Mean response } \\
\text { time (seconds). }\end{array}$ & 14. $5 \ldots$ & $22.0 \ldots$ & $21.7 \ldots$ & $14.7 \ldots$ & $16.7 \ldots$ & $30.5 \ldots$ & $11.7 \ldots$ & $34.0 \ldots$ & 56.6. \\
\hline
\end{tabular}

a The observer had been specifically requested to report the slightest difference he suspected, however small and doubtful, and say "neutral" or "matched" only when there was no suggestion of difference. small and doubtful, and say "neutral" or "matched" only when there was no sue

"Ratio of number of times the "blue" was used in naming the hue to the number of times the word "green" was used.

With this viewing arrangement a number of observers have looked at the specimens and have named, or attempted to name, their colors. The results are shown in table 4. Results on magnesium carbonate and magnesium oxide obtained at the same time and under the same conditions are also given for comparison. The oxide is so nearly neutral that observations such as these fail utterly to give any certain indication of hue, but the selectivity of reflectance is such as to tend to make the oxide appear blue. The carbonate is perceived as doubtfully yellowish or reddish, which is in accord with the slight selectivity of its reflectance as measured on this same instrument. Inspection of the table shows at once that the colors of all of the enamel specimens are perceived by all of the observers as "blue", "green", "bluegreen", or "green-blue", which, in general, is what would be expected from the data on selectivity of reflectance as given in figures 6,7 , and 8. On the basis of the data given under the caption "blue/green ratio" in table 4, we may perhaps summarize the results given in this table by the following compromise answers:

\begin{tabular}{|c|c|}
\hline Specimen & Hue \\
\hline $\begin{array}{l}63 \\
79 \\
114 \\
92 \\
48 \\
49\end{array}$ & $\begin{array}{l}\text { Distinctly bluish blue-green. } \\
\text { Bluish blue-green. } \\
\text { Blue-green. } \\
\text { Greenish blue-green. }\end{array}$ \\
\hline
\end{tabular}


It is of interest to note that there is perfect correspondence between these answers and the data on selectivity of reflectance shown in figure 7. The "mean response time" (average time elapsed from the moment the observer began to look until he announced his decision) is of some interest as indicating in a general way how much more readily the observer arrived at a decision for the enamel specimens than for the magnesium carbonate and magnesium oxide.

It will be noted in table 3 that the computed dominant wave length of specimen 4 was found to be $565.4 \mathrm{~m} \mu$. This leads us to expect its hue to be yellow-green rather than green or blue-green, as indicated above. Extensive further work was done with this sample and the following conclusion reached: Even for experienced observers, making the most critical judgments possible, the color difference (in a $6^{\circ}$ circular field) between specimen 4 and an ideal perfectly nonselective specimen of the same lightness under the same sunlight illumination is a doubtful, vanishingly small difference, the judgment of which results in changing decisions, sometimes the decision that the difference is nonexistent. It is established that the hue of specimen 4 for noon sunlight illumination lies within the spectral segment of the hue circuit between yellow and blue. From a statistical point of view, we may say that the hue of specimen 4 is most probably green, but that it may be either yellow-green or blue-green, dependent upon the brightness of the specimen field relative to the brightness of the comparison field, and also upon uncontrollable and unknown changes within the observer. Therefore, insofar as they can be made and have any significance, the direct comparisons of colors (as colors) are in accord with the data on selective reflectance; but the indications of the latter are more definite and subject to less uncertainty and ambiguity. As the departure of the specimen from perfect nonselectivity becomes progressively smaller the indications of color computed from measurements of spectral reflectance retain definiteness after the directly observed departure from gray by color sense in a $6^{\circ}$ circular field divided along a diameter has become indeterminate.

Washington, September 27, 1935. 